Discussion Paper No. 04-24

Unemployment Durations in West-Germany

Before and After the Reform of the Unemployment Compensation System During the 1980s

Bernd Fitzenberger and Ralf A. Wilke

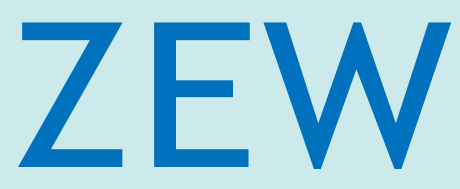

Zentrum für Europäische Wirtschaftsforschung $\mathrm{GmbH}$

Centre for European

Economic Research 
Discussion Paper No. 04-24

\title{
Unemployment Durations in West-Germany Before and After the Reform of the Unemployment Compensation System During the 1980s
}

\author{
Bernd Fitzenberger and Ralf A. Wilke
}

Download this ZEW Discussion Paper from our ftp server:

ftp://ftp.zew.de/pub/zew-docs/dp/dp0424.pdf

Die Discussion Papers dienen einer möglichst schnellen Verbreitung von neueren Forschungsarbeiten des ZEW. Die Beiträge liegen in alleiniger Verantwortung der Autoren und stellen nicht notwendigerweise die Meinung des ZEW dar.

Discussion Papers are intended to make results of ZEW research promptly available to other economists in order to encourage discussion and suggestions for revisions. The authors are solely responsible for the contents which do not necessarily represent the opinion of the ZEW. 


\section{Non-technical Summary}

Standard job search theory implies that longer entitlement periods for unemployment benefits increase the expected duration of unemployment spells until individuals accept a new job. This paper empirically analyzes the distribution of unemployment durations in West-Germany before and after the reforms of unemployment benefits during the mid 1980s. These reforms extended the maximum entitlement periods for unemployment benefits up to 32 months for elderly unemployed. The paper uses the comprehensive IAB employment subsample. Since unemployment is not directly observed in the data, we introduce two proxies: nonemployment (NE) and unemployment between jobs (UBJ). The analysis develops a theoretical framework in order to interpret differences between nonemployment and unemployment between jobs.

The empirical analysis shows that the effect of the reforms depend heavily on the definition of unemployment. In particular, we find that the risk of entering NE increased for the elderly after the reform whereas the risk of entering UBJ remained basically constant. Also the average NE duration for those individuals who were older than 53 years increased by $50 \%$ after the reform, whereas the average NE duration decreased by $25 \%$ for those individuals who were younger than 42 years. Interestingly, the ratio of the average UBJ durations between these groups remained constant. Surprisingly, we observe that the estimated survival functions (the survival function as a function of duration $T$ provides the share of those who are still unemployed after time $T$ among those who started out as unemployed) for remaining in UBJ did not change in response to the reform. We only observe an increase for the mid 1990s recession which is also the case for the younger unemployed. At the same time, the survival functions for remaining in NE increased dramatically, in particular for the elderly.

We provide a theoretical framework that explains our findings and we conduct a simulation study of the model which matches our empirical findings. We conclude that the NE duration for the elderly increased due to an increase in early retirement, whereas the duration did not increase among those who were still looking for a new job.

Our empirical results suggest that the common result of job search theory and the related empirical literature, longer entitlement periods for unemployment benefits increase the time until the unemployed accepts a new job, is not supported. Moreover, we do not observe that with longer entitlement periods for unemployment benefits individuals, who find a job, actually end up in more stable jobs or obtain higher earnings. We conclude that the additional expenses by the German federal labor office for the longer entitlement periods yield an advantage for two groups: companies, who disband their elderly employees using subsidized early retirement packages and the elderly unemployed who lost the incentive to look for a new job using the extensive early retirement 
packages. Since the elderly employees did approve of such generous retirement packages, they didn't insist on their dismissal protection. This is a typical win-win situation on the expense of the general public. 


\title{
Unemployment Durations in West-Germany Before and After the Reform of the Unemployment Compensation System during the 1980s
}

\author{
Bernd Fitzenberger* \\ Ralf A. Wilke
}

\begin{abstract}
March 2004
Abstract

This paper empirically analyzes the distribution of unemployment durations in WestGermany before and after the changes during the mid 1980s in the maximum entitlement periods for unemployment benefits for elderly unemployed. The analysis is based on the comprehensive IAB employment subsample containing register panel data for about 500.000 individuals in West Germany. We introduce two proxies for unemployment, since the data do not involve a precise economic definition of unemployment. We provide a theoretical analysis of the link between the durations of nonemployment and of unemployment durations between jobs. In our empirical analysis we find significant changes in the distributions of nonemployment durations for older unemployed individuals. At the same time, the distribution of unemployment durations between jobs did not change in response to the reforms. Our findings are consistent with an interpretation that many firms and workers used the more beneficial laws as a part of early retirement packages but those workers who were still looking for a job did not reduce their search effort in response to the extension of the maximum entitlement periods. This interpretation is consistent with a simulation of our theoretical model under economically plausible assumptions.
\end{abstract}

Keywords: definition of unemployment, duration analysis, unemployment insurance JEL: C24, J64, J65

${ }^{*}$ University of Mannheim, ZEW, and IFS - Address: Department of Economics, University of Mannheim, 68131 Mannheim, Germany. E-mail: fitzenberger@wiwi.uni-frankfurt.de

†ZEW Mannheim - Corresponding author: Ralf Wilke, Zentrum für Europäische Wirtschaftsforschung (ZEW), P.O. Box 1034 43, 68034 Mannheim, Germany. E-mail: wilke@zew.de.

We gratefully acknowledge financial support by the German Research Foundation (DFG) through the research project "Microeconometric modelling of unemployment durations under consideration of the macroeconomic situation". Thanks are due to Elke Lüdemann for excellent research assistance. We thank Gerard v.d. Berg and Alfred Garloff for helpful comments as well as a number of employees in the employment offices at Duisburg, Freiburg, Gelsenkirchen, Mannheim, and Oberhausen for many useful information. All errors are our sole responsibility. 


\section{Introduction}

Standard job search theory implies that longer entitlement periods for unemployment benefits increase the expected duration of unemployment spells until individuals accept a new job (see Katz and Meyer, 1990, for a survey). A number of institutional changes in the West German unemployment compensation system were enacted between 1985 and 1987. ${ }^{1}$ The probably most important change was the extension of the maximum entitlement period for unemployment benefits in the case of elderly unemployed (table 1). The transition was stepwise over the years 1985-1987 for the different age groups. Since the maximum entitlement periods for unemployment spells starting in 1984 or later was also ex-post extended, it is expected to find smoother transitions in the data and not a single jump. The unemployment durations started in 1983 were the last to which only the old law applied. The analysis here is about the effects on unemployment durations due to these reforms. The paper is highly policy relevant since a reduction in benefit entitlement periods is currently implemented by policy makers in Germany to effectively undo most of the institutional changes in the 1980s in an effort to reduce the level of unemployment in Germany.

A number of studies have already pursued an empirical analysis of unemployment duration before and after the reform under consideration (Hunt, 1995, Hujer and Schneider, 1995, Steiner, 2001 and Plaßmann, 2002). Most of these papers are based on the German Socio-Economic Panel $(\mathrm{GSOEP})^{2}$ and apply single spell parametric (mixed-)proportional hazard models for the exit from unemployment. ${ }^{3}$ The estimated effects of the reform of the unemployment compensation system mainly point to the direction that longer entitlement periods for unemployment benefits result in lower re-employment rates and therefore in longer unemployment duration. Hunt (1995) finds that workers aged 44-48 increased their unemployment duration greatly relative to younger workers. She also finds that the effect for the 49-57 year-old workers was smaller. Hujer and Schneider (1996) find that aged 44-48 have significantly smaller hazards for re-employment relative to the younger workers. Steiner (2001) and Plaßmann (2002) have similar findings for elderly unemployed. Steiner (2001) concludes that the results are in accordance with one of the main implications of job-search theory, i.e. unemployment durations increase when entitlement periods are extended. There are also several contributions with related topics using survey data from other countries. Empirical studies for the United States suggest a positive effect of the potential duration and the benefits level on the expected duration of unemployment (Katz and Meyer, 1990,

\footnotetext{
${ }^{1}$ For a detailed description of the German unemployment compensation system and of the conducted reforms, see Hunt (1995) and Plaßmann (2002).

${ }^{2}$ Only Plaßmann (2002) uses the IAB employment subsample 1975-1995.

${ }^{3}$ Van den Berg (2001) stresses that the interpretation of the results of single spell (mixed-)proportional hazard models are often unstable and should be performed with extreme caution.
} 
and Solon, 1985). Narendranathan, Nickell and Stern (1995) find for Britain a positive elasticity of expected unemployment duration for men with respect to the level of unemployment benefits. The effect depends on the age and is smaller for the $>45$ years old. They do not find an impact for the long term unemployed. Van den Berg (1990) obtains positive elasticities using data from the Netherlands in a non-stationary job search model. The elasticities are greater after two years of duration time.

This paper pursues a descriptive empirical analysis based on comprehensive German register data, the IAB employment subsample, which contains panel data for about 500.000 individuals for West-Germany during the period 1975-1997. We make use of the extreme richness of the data and we avoid risky parametric models by performing non-parametric estimations which are less likely subject to misspecification of the functional form. The findings suggest that the strong increases in maximum benefit entitlement periods for older workers in West-Germany during the 1980s did not extend the duration until unemployed workers found a new job among those who were still looking for a new job. The effect was rather to extend the duration of nonemployment effectively leading the way to early retirement and withdrawal from the labor market.

Concretely, we find the following: The average nonemployment durations for elderly unemployed (>53 years) increased between 1981 and 1993 by 50 percent, whereby the average nonemployment duration of younger unemployed ( $<42$ years) decreased by about 25 percent. For the other age groups it remained constant. At the same time the average duration of temporary unemployment remained constant over the period for all age groups. In particular in the business manufacturing sector the probability for staying in nonemployment has increased for the elderly to a dramatical level of about $90 \%$. This is probably due to a sharp increase in the use of early retirement packages. The extension of the maximum entitlement of unemployment insurance has only a limited influence on the distribution of the length of temporary unemployment durations, i.e. we do not observe that elderly individuals spend more time in unemployment before they accept a new job. Moreover, if elderly unemployed accept a new job, they do it on average faster than their younger colleagues. We also observe that the length of employment spells after a period of temporary unemployment did not increase for the age groups with longer entitlements in comparison. Moreover, the post-unemployment earnings for the aged $42-65$ unemployed did not increase after the reform relative to the earnings of the aged $<42$. This indicates that the matching quality between employee and job has not improved after the reforms. We conclude that the additional expenses by the German federal labor office yield an advantage for two groups: companies, who disband their elderly unemployed using subsidized early retirement packages and the elderly employees who lost the incentive to look for a new job using the extensive early retirement packages. 
The remainder of this paper is structured as follows: Section 2 describes the data and the institutions. Nonemployment and unemployment-between-jobs are defined in section 3 as two proxies for unemployment available in the data. Section 4 develops a theoretical model to analyze differences between the two proxies. Transitions from employment to unemployment are analyzed empirically in section 5. Section 6 discusses the distribution of unemployment durations and section 7 performs the survival analysis. Job stability and wages in employment after unemployment are analyzed empirically in section 8 . Section 9 concludes and the appendix contains further institutional information and the detailed empirical findings.

\section{Data and Institutions}

The data used for the analysis is the IAB Employment Subsample (IAB-Beschäftigtenstichprobe 1975-1997 [Regionalfile], IABS). A basic description of the data set can be found in Bender et al. (2000). ${ }^{4}$ The data contain daily register data of about 500.000 individuals in West-Germany on their employment spells and the spells during which they receive transfer payments from the labor offices. It is a representative sample of employment subject to social security taxation and, therefore, it is not representative with respect to periods of nonemployment. Employment periods are based on the register records of the public pension funds which obtain from the companies the relevant information about employment spells subject to social security taxation. Periods of self employment and employment as life-time civil servants (Beamte) are not included in the data.

Periods of registered unemployment - or economically more meaningful concepts of unemployment (e.g. according to the ILO standard) - can not be identified from the data. The German federal labor office has added instead the periods in which the individuals obtain some kind of income transfer payment. The data records spells involving the following three types of transfer payments:

1. Unemployment benefits UB ("Arbeitslosengeld"),

2. Unemployment assistance UA ("Arbeitslosenhilfe"), and

3. Income Maintenance during training IMT ("Unterhaltsgeld"). This is paid during participation in public sponsored training as a part of active labor market policy.

\footnotetext{
${ }^{4}$ These data are also used by Plaßmann (2002) to analyze unemployment duration. To sharpen our understanding of the data generating process, one of the authors (R. Wilke) visited some unemployment offices in different parts of West Germany.
} 
Our discussion of institutions refers to the setup between 1981 and 1997 which differs from the situation today. ${ }^{5}$ The analysis in this paper is restricted to the years 1981 to 1997 because the information about spells with transfer payments is likely to be incomplete before that time, see Bender et al. (2000) and the references given there.

The three types of transfer payments differ with respect to the income replacement ratio and as to whether they are means tested. UB as well as IMT are paid as certain percentage (between 60 and $67 \%$ ) of past earnings and they are generally not means tested. UA involves a somewhat lower replacement ratio (between 53 and $58 \%$ in the period of consideration) and it is means tested. Provided that individuals had sufficiently long employment spells before they become unemployed they are eligible for UB for the maximum entitlement periods depicted in table 1. After the end of the maximum entitlement periods, they would become eligible for the lower UA only if their family had no other source of income and no wealth (means tested). Until 1997 also participation in training did not only provide a source of income through receipt of IMT but it itself did also renew the entitlement for UB - just as if the unemployed individual had been working.

Unfortunately, the data only involve spell information on the fact whether transfer payments were received but do not provide the information on the level of these payments. Evidence reported in Franz (2003, table 7.9) suggests that the actual replacement ratios are typically lower than the nominal ratios mentioned above. This is mostly due to temporary (6-12 weeks) or permanent sanctions ("Sperrzeiten") which are mainly applied for two reasons. First, when an unemployed worker quits voluntarily, he becomes eligible for UB only after a while. Second, when an unemployed worker rejects an acceptable job offer, he is punished by losing UB for a while. The IABS reports these periods of no UB receipt as a late start or as interruption in the spells of transfer payments. Wilke (2003) provides a descriptive analysis of sanctions in the IAB-Employment subsample.

In order to reduce the labor supply and "free jobs for young workers", government policy allowed receipt of UB as an intermediate step between employment and early retirement. While being on UB, social security taxes were still paid for unemployed individuals and they were still accumulating claims on social security payments after retirement. In addition, the discount on social security payments after early retirement, i.e. before the official retirement age at 65 years, was actuarially biased in favor of early retirement (see table 1 in Berkel and Börsch-Supan,

\footnotetext{
${ }^{5}$ Also during the time period under consideration a number of changes were enacted in addition to the extension of the benefit entitlement periods. For instance, the income replacement ratios for UB and UA were reduced in the case of unemployed individuals without children and increased in the case of unemployed individuals with children, see Hunt (1995). The income replacement ratio for IMT was above the ratio for UB at the beginning. It was reduced a number of times so that for most of the time period under consideration it was equal to the ratio for UB.
} 
2003). Thus, during the mid 1980s receipt of UB was becoming the stepping stone towards early retirement for workers at an age above 55 years (see Koller et al., 2003, for a recent account of this). Hunt (1995) finds some evidence for this using survey data (GSOEP) but she does not analyze this issue in detail.

The data provide no information on spells when an individual is registered as unemployed and is not entitled to transfer payments from the labor offices as well as whether she receives welfare payments ("Sozialhilfe"). This is particularly relevant for an analysis of long-term unemployment which in cases without transfer payments in the data can not be reasonably distinguished from having left the labor force.

\section{Proxies for Unemployment}

Since the data does not allow for an economically meaningful, exact assessment as to whether an individual is unemployed or out of labor force, we use the two extreme benchmarks nonemployment and unemployment-between-jobs to analyze the changes in the duration of unemployment. The common definition "registered unemployment" cannot be used because there is not sufficient information in the data. The two benchmarks are operationalized as follows:

1. Nonemployment (NE): all periods of nonemployment after an employment period which contain at least one period with income transfers by the German federal labor office. The nonemployment period is considered as censored if the last record involves a UB, UA, or IMT payment that is not followed by an employment spell. ${ }^{6}$ In this case we do not know whether the individual is still unemployed, out of labor force or maybe self-employed. With this definition of unemployment we include the periods of nonemployment (out of the labor force, social benefits) which are not explicitly recorded in the data. From 1980 to 1997, a total number of 371.317 nonemployment periods are observed in the IABS.

2. Unemployment between jobs (UBJ): all episodes between two employment spells during which an individual continuously receives UB, UA, or IMT payments. Interruptions of these payments can be up to four weeks - in the case of cut-off times: six weeks. With this definition it is ensured that the individuals are continuously registered as unemployed. Note that this sample does not include many registered unemployed, in particular long term unemployed. From 1980 to 1997, a total number of 204.954 UBJ spells are observed in the IABS.

\footnotetext{
${ }^{6} \mathrm{~A}$ nonemployment spell is treated as right censored if it is not fully observed.
} 
These two definitions provide benchmarks on the length of unemployment taking account of the fact that not all unemployed are successful in finding a new job during the period of observation (therefore the UBJ definition can not be used alone) and of the fact that unemployed individuals may leave the labor force. In order to proxy for the unemployment period when people eventually leave the labor force, the NE definition assumes that unemployment ends after the exhaustion of transfer payment and the only usable information is then that unemployment is right censored at this point. However, this definition also entails the possibility that individuals might have left the labor force earlier, i.e. they are not interested in a new job any more, and they just keep receiving the transfer payments because the labor offices can not sanction this behavior. ${ }^{7}$ In contrast, the UBJ definition excludes cases where a job is found some time after the end of the entitlement to transfer payments. This allows us to focus on the link between benefit entitlement periods and finding a job. The definition also excludes cases where people leave the labor force after the end of the entitlement period and later find a job. The next section analyzes the link between the length of unemployment, NE, and UBJ based on a theoretical model.

\section{Determinants of Nonemployment and Unemployment between Jobs}

Ideally, our empirical analysis should investigate the determinants of unemployment. However, we cannot observe unemployment in the available data (see previous section) and, instead, we analyze both nonemployment (NE) and unemployment-between-jobs (UBJ) as benchmarks. This section treats both durations as the outcome of a competing-risks-model in order to discuss the link between the duration of unemployment and what we actually estimate for NE and UBJ.

\subsection{Basic model}

The issue of linking the two proxies for unemployment is analyzed by means of the following competing-risks-model

$$
t=\min \left(t_{E}, t_{O}\right)
$$

\footnotetext{
${ }^{7}$ See Wilke (2003) for an analysis of sanctions when unemployed individuals do not take an acceptable job offer. This study shows that sanctions to a large extent seem ineffective due to a high withdrawal rate.
} 
where $t$ is the possibly unobserved unemployment duration,

$t_{E}$ is the time until a new job is taken, and

$t_{O}$ is the time until individual leaves the labor force.

Both definitions NE and UBJ provide possibly censored observations on the duration of unemployment $t$. NE entails an information loss due to many individuals being right censored and due to the possibility that individuals who are receiving transfer payments might not be searching for a job any more. Otherwise NE involves no further restriction on the observability of $t$ thus we treat in the following $t$ as the length of NE. In contrast, UBJ involves no right censored durations but this definition conditions the observability of $t$ on the outcome $t_{E}<t_{O}{ }^{8}$

How is the economically meaningful concept of unemployment captured in this model and what are the effects we are looking for in our analysis of unemployment? Incentive effects of unemployment benefits derived from search theory operate mainly through the job finding duration $t_{E}$, which represents the economic concept of unemployment. However, it is conceivable that the exit rate out of labor force is indirectly affected by changes in unemployment benefits, e.g. when benefits are extended it is rational to postpone an exit out of labor force. The effects of stronger incentives for early retirement by elderly workers are just opposite. Such incentives reduce the duration until the exit out of labor force and, at the same time, they reduce the incentives to search for a new job, thus increasing $t_{E}$. What we are looking for in our empirical analysis is evidence for such differential effects on $t_{E}$ and $t_{O}$. This evidence can only be indirect since $t_{E}$ and $t_{O}$ are not directly observed. Instead of estimating a structural competing risks model requiring a number of modeling assumptions, which are difficult to justify based on first principles, we investigate the implication of this model on the observable NE and UBJ durations.

For simplicity of the argument, let us assume that both $t_{E}$ and $t_{O}$ are exponentially distributed, independent random variables with hazard rates $\lambda_{E}$ and $\lambda_{O}$, respectively. Then, it follows immediately that $t$ is exponentially distributed with hazard rate $\lambda=\lambda_{E}+\lambda_{O}{ }^{9}$ This links the exit rates to employment $\lambda_{E}$ and to out-of-labor-force $\lambda_{O}$ with $\lambda$ as the exit rate of the duration of the NE spells .

UBJ spells are observed conditional upon $t_{E}<t_{O}$, thus the following argument links $\lambda_{E}$ and $\lambda_{O}$ to the duration of the UBJ spells. The probability that an observed UBJ spell is longer than

\footnotetext{
${ }^{8}$ In our empirical analysis, UBJ excludes cases where individuals find a job some time after the end of their benefit entitlement. Therefore, it is to be expected that the distribution function of UBJ according to the definition in the empirical analysis lies strictly to the left of the one for the definition used in the theoretical model. The main insights gained from the theoretical model - as to be seen later - will therefore apply a forteriori to the relationship between the empirical NE and UBJ distributions.

${ }^{9}$ To see this, note $P(t>T)=P\left(t_{E}>T\right) \cdot P\left(t_{O}>T\right)=\exp \left(-\lambda_{E} T\right) \cdot \exp \left(-\lambda_{O} T\right)=\exp \left[-\left(\lambda_{E}+\lambda_{O}\right) T\right]$.
} 
$\mathrm{T}$ is given by ${ }^{10}$

$$
P\left(t_{E}>T, t_{E}<t_{O} \mid t_{E}<t_{O}\right)=\exp \left[-\left(\lambda_{E}+\lambda_{O}\right) T\right]
$$

Therefore, we obtain the possibly surprising result that UBJ and NE spell durations exhibit, in fact, the same exponential distribution with exit rate $\lambda=\lambda_{E}+\lambda_{O}$. Both durations are therefore affected in the same way by changes in the determinants of the job finding rate $\lambda_{E}$ and the exit rate from the labor force $\lambda_{O}$. Let $S_{N E}(T)$ and $S_{U B J}(T)$ be the survival functions of the NE and the UBJ durations, respectively, and let $z$ be a variable affecting $\lambda_{E}$ and $\lambda_{O}$, then one obtains

$$
\frac{\partial S_{N E}(T)}{\partial z}=\frac{\partial S_{U B J}(T)}{\partial z}=-T \cdot \exp \left[-\left(\lambda_{E}+\lambda_{O}\right) T\right]\left(\frac{\partial \lambda_{E}}{\partial z}+\frac{\partial \lambda_{O}}{\partial z}\right)
$$

Based on this result, the effects of an increase in unemployment benefits or in incentives for early retirement is ambiguous both for NE and UBJ durations. It is highly plausible that with unemployment benefits the effect through $t_{E}$ dominates, i.e. NE and UBJ durations increase in response to an extension of unemployment benefits, and vice versa with incentives for early retirement the effect through $t_{O}$ dominates, thus, the introduction of early retirement benefits reduces both NE and UBJ durations.

The main result in this subsection, namely, that NE and UBJ durations exhibit the same distribution is neither helpful to assess differential effects on NE and UBJ duration nor to infer something about the effects on $t_{E}$ and $t_{O}$ durations. The equality of the NE and UBJ distribution hinges critically on the absence of unobserved heterogeneity, as we will show in the next subsection. Also a deviation from the assumption of a constant hazard rate for both risks results in differences between NE and UBJ. The direction of the difference is ambiguous and this is something we will not base our empirical analysis upon. ${ }^{11}$ For the clarity of the theoretical argument and because of the economic plausibility of the importance of unobserved heterogeneity, we stick in the following to the case of constant hazard rates. Finally, it has to be noted as well that the definition of NE durations, when individuals do not find a job (see previous section), also entails the possibility that individuals might have left the labor force earlier than the end of transfer payments. This effect would result in an upward bias in the observed NE distribution.

\footnotetext{
${ }^{10}$ To see this, note $P\left(t_{E}<t_{O}\right)=\frac{\lambda_{E}}{\lambda_{E}+\lambda_{O}}$ and

$$
P\left(t_{E}>T, t_{E}<t_{O}\right)=\int_{T}^{\infty} \int_{t_{E}}^{\infty} \lambda_{E} \exp \left(-\lambda_{E} t_{E}\right) \lambda_{O} \exp \left(-\lambda_{O} t_{O}\right) d t_{O} d t_{E}=\frac{\lambda_{E}}{\lambda_{E}+\lambda_{O}} \cdot \exp \left[-\left(\lambda_{E}+\lambda_{O}\right) T\right] .
$$

${ }^{11}$ Generally speaking, one obtains the intuitive result that the UBJ distribution lies strictly to the left (to the right) of the NE distribution, if the distribution of $t_{e}$ durations lies to the left (to the right) of $t_{o}$ durations and the variance of both distributions is small. The part about the variance is crucial because the result is just reversed when variances are large. Simulation results of both types for lognormal distributions are available upon request.
} 


\subsection{Unobserved heterogeneity}

Our subsequent empirical results show that the survival function of NE durations is larger than that for UBJ durations for all subgroups considered. As indicated at the end of the last subsection, this could be the outcome of a particular deviation from the assumption of a constant hazard rate for both risks. Our focus lies, however, on the fact that unobserved heterogeneity, introduced in a particular way, is consistent with our empirical findings.

The introduction of unobserved heterogeneity changes the comparison between the NE and UBJ duration for the case of constant hazard rates, see Van den Berg (2001) for a recent survey on duration models illustrating the importance of unobserved heterogeneity. We allow here for the simplest distribution of unobserved heterogeneity just involving two types of workers, i.e. a mass point distribution with two types. ${ }^{12}$ Assume for the hazard rates into employment and out of labor force

$$
\lambda_{E}(\alpha)=\bar{\lambda}_{E}+\alpha \quad \text { and } \quad \lambda_{O}(\alpha)=\bar{\lambda}_{O}-l \cdot \alpha
$$

where $\alpha$ represents the unobserved heterogeneity part, $\bar{\lambda}_{E}$ and $\bar{\lambda}_{O}$ are the systematic parts of the hazard rates, and $0<l<1$. This specification involves a negative correlation between the two hazard rates. It is plausible that unobserved characteristics which positively affect the job finding rate are negatively correlated with the propensity to leave the labor force. Since $l<1$, it is also assumed that the effect on the job finding rate is stronger than on the exit rate from the labor force. The setup here corresponds to the discussion of differential effects on $t_{E}$ and $t_{O}$ in the previous subsection. We assume a distribution with two mass points $P\left(\alpha=\alpha_{j}\right)=p_{j}$ with $j=1,2, p_{1}+p_{2}=1$, and $\alpha_{1}>\alpha_{2}$, i.e. the $\alpha_{1}$-type individuals are more likely to find a job and less likely to leave the labor force compared to the $\alpha_{2}$-types.

Based on the results above, the survival functions of the NE and the UBJ durations for the different $\alpha$-types is given by

$$
S_{N E}(T \mid \alpha)=S_{U B J}(T \mid \alpha)=\exp \left\{-\left[\bar{\lambda}_{E}+\bar{\lambda}_{O}+(1-l) \alpha\right] T\right\}
$$

However, this does not imply that the distributions of the observed durations for which $\alpha$ is integrated out are also the same. In fact, it is now shown that the survival function of NE duration lies strictly to the right of the survival function of UBJ durations, i.e. $S_{N E}(T)>S_{U B J}(T)$ for all $T$. Therefore, UBJ spells seem to end quicker than NE spells in the presence of unobserved heterogeneity.

\footnotetext{
${ }^{12}$ Differences in observed characteristics can be dealt with in standard ways by stratifying the data according to the observed characteristics (or using regression type methods). The equality of the two distributions then holds within each stratum.
} 
To show this, note that for NE durations by the law of iterated expectations

$$
S_{N E}(T)=\sum_{j=1}^{2} p_{j} \exp \left\{-\left[\bar{\lambda}_{E}+\bar{\lambda}_{O}+(1-l) \alpha_{j}\right] T\right\}
$$

To analyze the survival function for UBJ durations, note that

$$
S_{U B J}(T)=P\left(t_{E}>T \mid t_{E}<t_{O}\right)=\frac{P\left(t_{E}>T, t_{E}<t_{O}\right)}{P\left(t_{E}<t_{O}\right)} .
$$

For the two probabilities in the last expression, one obtains (see footnote 10)

$$
P\left(t_{E}<t_{O}\right)=\sum_{j=1}^{2} p_{j} \frac{\bar{\lambda}_{E}+\alpha_{j}}{\bar{\lambda}_{E}+\bar{\lambda}_{O}+(1-l) \alpha_{j}}
$$

and

$$
P\left(t_{E}>T, t_{E}<t_{O}\right)=\sum_{j=1}^{2} p_{j} \frac{\bar{\lambda}_{E}+\alpha_{j}}{\bar{\lambda}_{E}+\bar{\lambda}_{O}+(1-l) \alpha_{j}} \exp \left\{-\left[\bar{\lambda}_{E}+\bar{\lambda}_{O}+(1-l) \alpha_{j}\right] T\right\}
$$

Hence,

$$
S_{U B J}(T)=\sum_{j=1}^{2} \tilde{p}_{j} \exp \left\{-\left[\bar{\lambda}_{E}+\bar{\lambda}_{O}+(1-l) \alpha_{j}\right] T\right\}
$$

with "adjusted weights"

$$
\tilde{p}_{j}=\frac{p_{j} \frac{\bar{\lambda}_{E}+\alpha_{j}}{\lambda_{E}+\bar{\lambda}_{O}+(1-l) \alpha_{j}}}{\sum_{k=1}^{2} p_{k} \frac{\bar{\lambda}_{E}+\alpha_{k}}{\lambda_{E}+\bar{\lambda}_{O}+(1-l) \alpha_{k}}} \quad \text { for } \quad j=1,2 .
$$

Since $\alpha_{1}>\alpha_{2}$, it follows that $\tilde{p}_{1}>p_{1}$ and $\tilde{p}_{2}<p_{2}{ }^{13}$ and, therefore, $S_{U B J}(T)<S_{N E}(T)$. From this result we can easily infer that an increase in the dispersion of $\alpha_{1}$ and $\alpha_{2}$ for given weights $p_{j}$ with $j=1,2$ results in a larger difference between $S_{U B J}(T)$ and $S_{N E}(T)$.

This result can be motivated as follows. Since we assume some form of unobserved heterogeneity which affects UBJ durations more strongly than NE duration, the quicker exits of the $\alpha_{1}$-types to employment results in the UBJ population having a larger share of $\alpha_{1}$-types than the population of all individuals corresponding to the NE population. Therefore, on average the individuals in the UBJ population exhibit shorter durations which is captured by the adjusted weights $\tilde{p}_{j}$.

\footnotetext{
${ }^{13}$ This result follows from the simple fact that$$
\frac{\frac{1-x}{a-x(1-l)}}{\frac{1+y}{a+y(1-l)}}<1
$$

for $a>1, x, y>0, l>0$, provided that the expressions $1-x, a-x(1-l)$, and $a+y(1-l)$ are strictly positive.
} 
To finish this subsection, how does the introduction of unobserved heterogeneity change the comparative statics for the observed NE and UBJ survival functions. It is clear, that for NE durations $\frac{\partial S_{N E}(T)}{\partial z}$ is just a weighted average of expressions as in equation (2) where the weights are the probabilities $p_{j}$. For UBJ duration, $\frac{\partial S_{U B J}(T)}{\partial z}$ also involves the effect of a change in $z$ on the adjusted weights $\tilde{p}_{j}$. It is therefore not possible to sign unambiguously the difference between the changes in the two durations. For instance, a reduction in job finding rates $\bar{\lambda}_{E}$ can possibly result in a stronger increase of NE durations compared to UBJ durations.

\subsection{Simulation results}

Anticipating our major empirical finding, for older individuals NE durations but not UBJ durations have became relatively longer compared to younger individuals between the 1980s and 1990s. How can this finding be rationalized within our model setup in light of the policy changes discussed in the introduction? This subsection illustrates a plausible mechanism by means of a simulation of our model.

For the simulation, we assume that there exist two subgroups of workers, the treatment group (the older workers) and the control group (the younger workers). ${ }^{14}$ These two groups can be identified in the data. We make the economically plausible assumption that for the treatment group, the job finding rates are lower and the exit rates out of the labor force are larger compared to the control group, i.e. the specific hazard rates used for the simulation are given by

$$
\lambda_{E}=0.3+\alpha(T R E A T) \quad \text { and } \quad \lambda_{O}=0.2-0.4 \cdot \alpha(T R E A T)
$$

and $T R E A T=1$ for the treatment group and $T R E A T=0$ for the control group. Further, an individual belongs with probability 0.5 to either the treatment or the control group. Concretely, we assume

$$
\alpha(T R E A T)= \begin{cases}\alpha_{1}=0 & \text { with probability } p_{1}=0.5 \text { irrespective of treatment status } \\ \alpha_{2}(T R E A T) & \text { with probability } p_{2}=0.5\end{cases}
$$

where $\alpha_{2}(0)=-0.1$ and $\alpha_{2}(1)=-0.14$. For the $\alpha_{2}$-types in the treatment group, the policy change increases the propensity to leave the labor force and it decreases the job finding rate. There is no change for the control group as well as for the $\alpha_{1}$-types in the treatment group. Also, the share of $\alpha_{2}$-types does not change in either group.

\footnotetext{
${ }^{14}$ These labels are motivated by the fact that older workers were affected by various policy changes. Both incentives for early retirement and unemployment benefit entitlement periods did increase strongly over time for this group.
} 
This setup is motivated by the following interpretation of the actual policy changes in Germany. For older individuals, the combination of an extension of unemployment benefits and an increase of incentives for early retirement did strongly increase the propensity to leave the labor force and reduce the job finding rate for the subgroup of individuals characterized by low labor force attachment (" $\alpha_{2}$-types"). In contrast, older individuals with a high labor force attachment (" $\alpha_{1}-$ types") were barely affected by these changes.

We simulate the above model for a random sample of 400,000 observations to obtain a good estimate of the survival functions implied by the model. The results are depicted in figure 1 . The first two graphs provide the survival functions of NE and UBJ durations both for the treatment and the control group before and after the simulated policy change, respectively. Before the policy change, the NE survival curve is strictly to the right of the UBJ survival curve for both groups but for the control group this difference is not visible. After the change, the difference between NE and UBJ is larger for the treatment group. This is to be expected since the dispersion of the unobserved heterogeneity distribution increases. The third graph shows that the NE survival function for the treatment group moves strictly to the right. In contrast, and possibly surprising at first glance, the UBJ survival function moves strictly to the left for the most part of the distribution and the change is strongest in the upper part of the distribution. Thus, our modelling setup implies an increase in NE durations and no increase (in fact a decline) in UBJ durations even though the job finding rates decline for a subgroup of workers.

The substance of our result, namely that NE durations increase more strongly than UBJ durations, does not change when we allow the share of $\alpha_{2}$-types to increase (this is likely to occur since older individuals might increasingly become unemployed due to stronger early retirement incentives) and when the job finding rate also declines for the $\alpha_{1}$-types due to the longer benefit entitlement periods (the latter effect is likely to be small since the vast majority of UBJ durations are considerably shorter than the longer benefit entitlement periods). We investigated the sensitivity of the results by further simulations which are available upon request.

\section{Transitions from employment to unemployment}

Elderly workers in West-Germany enjoy substantial employment protection in the period under investigation. It is very difficult to lay off elderly employees once they have a certain tenure. The risk of unemployment for this group of individuals should therefore be quite low. It is also important to mention that there is a pool of elderly unemployed (currently aged 58 or above) who receive unemployment benefits - irrespective of their entitlement based on their employment history - if they commit not to search for a new job. Elderly unemployed therefore have the option 
to receive unemployment benefits until they are entitled for transfers from the pensions system and during this period they are not counted as unemployed in the official statistics.

Figure 2 presents the average risk of unemployment for 40-62 aged employees for the two definitions of unemployment in selected years with rather different macroeconomic environments. ${ }^{15}$ It becomes apparent that the risk of UBJ is almost independent of the age of the unemployed and of the year, whereas the risk of nonemployment varies sharply. First, it is observed that the risk of nonemployment has a peak between age 55 and 59. In 1981, the peak is only evident for age 59. In 1985 and 1990 the magnitude of the peak reduces but the dispersion increases and it shifts to the left. The shift to the left and the increased dispersion are due to the extension of the unemployment insurance payment. This is because even workers who loose their job at age 55 after the reform are able to reach the critical age limit 58 without interruption of unemployment benefits transfers. In 1995, the magnitude of the peak sharply increases. This is due to recession in the mid 1990s. Moreover, the 55-60 aged employees exhibit uniformly higher risks of nonemployment. The risk of nonemployment is in particular high in the manufacturing sector and even in the public sector the risk of nonemployment increased in the 1990s (see figure 3).

The different results for the two definitions of unemployment suggest that in particular, in bad economic environments unemployment benefits are used as an integral part in early retirement packages. Due to the reform of the maximum entitlement period, the peak of the NE risk shifted to the left, i.e. the early retirement is offered to the employees several years earlier. Moreover, since the reform the ratio of the UBJ risk relative to the NE risk decreased in particular for the elderly (see figure 4). For the age group > 53, this ratio decreased by 50\% from 1985 until 1995, whereas the decrease for the other age groups (apart from the group 49-53) is in the range of 15\%. This shows that even in the years with a good macro economic environment $(1985,1990)$ the overall ratio of employees aged $>53$ entering UBJ given that they enter NE has decreased after the reform.

\section{Distribution of unemployment duration}

For the unemployment durations starting in 1981 and 1994, the histograms in figure 5 present the empirical distributions over the first three years $(\approx 1.095$ calender days $)$. The upper panel shows the nonemployment (NE) spells and the lower panel the unemployment between jobs (UBJ) spells. The censored observations are included in the distribution of NE durations. It is important to note that there are small mass points at 12 months (1981 and 1994) and 32 months (1994) in the

\footnotetext{
${ }^{15}$ See Wilke (2004) for a more detailed analysis of the impact of changing macro conditions on the risk of unemployment for the 26-41 aged workforce.
} 
distribution of NE spells. These mass points are directly related to the maximum UB entitlements periods: a considerable number of NE spells are censored at the end of the UB entitlement period. Interestingly, mass points at these durations are not observed for UBJ spells. This suggests that job searchers usually do not wait until the exhaustion of their UB entitlement period before they accept a new job.

Figure 6 presents the average unemployment durations for the age groups of table 1 from 1981 to 1993. It is evident that average NE duration for $>53$ years old unemployed has increased by $50 \%$ over this period whereas the average NE duration for the $<42$ years old declined by $25 \%$. For the other age groups, the average NE duration declined during the 1980s and sharply increased after the German reunification in the 1990s. This is most likely due to macroeconomic changes. Considering the average UBJ durations, one observes the same variation due to the business cycle but, at the same time, the older unemployed (> 53 years) leave unemployment faster on average than all other age groups. This property does not change over time and is therefore not affected by the reforms under consideration. Note that figures for the years after 1993 are not reported due to the censoring of the data at the end of 1997.

Table 2 reports the observed number of unemployment spells for the different age groups. Most noticeable is the sharp increase of the NE spells for the age group $>53$ years, i.e. the inflows into NE spells but not into UBJ spells have increased strongly over time. This is also in accordance with the findings of the foregoing section.

\section{Survival analysis}

This section presents estimates of survival functions, which report the probability of remaining in NE and in UBJ, respectively, after a given duration. The Kaplan-Meier-estimator takes account of the inherent censoring for NE durations. An upward movement of the survival functions means that the probability of leaving unemployment has decreased. ${ }^{16}$

The following figures present selected representative survival function estimates for the 1980s and 1990s (until 1995) for the age groups considered. Figure 7 (left, upper panel) shows that the NE survival function did not change much for the $<42$ years old. The estimated survival curves are higher for bad years (1981,1995: bad in the sense of the labor market conditions) and lower for good (see above) years $(1985,1990)$. For the age groups $42-43$ and $44-48$ we observe similar changes apart from that survival functions increase in the labor market slowdown of the mid 1990s (figure 7, left, middle and bottom). For the age group 49-53 the increase in the mid

\footnotetext{
${ }^{16}$ A detailed Kaplan-Meier unemployment survival analysis of the West-German 26-41 aged workforce can be found in Wilke (2004).
} 
1990s is sharper (figure 8, left, up). Considering the age group $>53$, it is apparent that the NE survival functions continuously increased over the 15 years under consideration and they did so even in the boom year after the reunification (figure 8, left, bottom). Interestingly, at the same time, the UBJ survival curves of the elderly (> 53 years) remained almost constant(!) (figure 8, right, bottom). We observe similar patterns for the other age groups and the survival curves in the mid 1990s increased a bit for all groups including even the younger unemployed. It is not evident from these results that the increase is due to the reform between 1985-1987. It seems to be caused by a structural change due to the bad macroeconomic environment. Since the increase of the UBJ survival functions is a bit greater for the aged 42-53 than for the young unemployed it might be the case that the reform shows an effect in a weak macroeconomic situation only. Surprisingly, as explained by our theoretical model, we do not observe this for the $>53$ aged.

Figure 9 shows that the survival curves vary sharply over the sector of last employment before entering unemployment. For the manufacturing sectors ${ }^{17}$, the survival curves for the age group $>53$ increased up to more than 0.9 after three years (figure 9, up, left), while this probability is only about 0.6 for the other sectors ${ }^{18}$ (figure 9 , bottom, left). The sharp increase of the survival functions, in particular in the manufacturing sector, is probably directly related to the massive early retirement programs which were conducted at this time. Considering the survival functions of those in UBJ (figure 9, right), it is obvious that the survival curves remained almost constant over time with some increase in the manufacturing sector in the mid 1990s.

Considering the empirical survival functions for the age group $>53$ years in figure 10, the effect of the reform on the observed length of NE becomes apparent immediately. The jumps at the maximum length of UB entitlements are shifted to the right after the reform. This shift is particularly obvious for the manufacturing sectors, ${ }^{19}$ where the empirical survival function is shifted about 20 months to the right. The jumps for NE (being absent for UBJ) reflect that many observed spells end at the the maximum entitlement periods and are thus due to the administrative rules. It follows that many elderly nonemployed then drop out of the labor force or they are not eligible for further unemployment benefits. From figure 8 (right, bottom) it was already apparent that most of them did not re-enter into regular employment.

\footnotetext{
${ }^{17}$ Production of durables, consumption goods and base materials.

${ }^{18}$ Agriculture, energy, mining, nutrition, construction, traffic, communication, services, public sector, with trade excluded.

${ }^{19}$ During the period 1985 to 1987 the maximum length of entitlements was increased step by step from 12 to 32 months. This pattern is clearly visible in figure 10 (left).
} 


\section{Employment stability and wages after unemployment}

Employment periods after unemployment could possibly be affected by the policy change. This can be assessed by analyzing the length of the following employment spells (employment stability) and the changes in earnings after unemployment compared to before unemployment. Figure 11 reports the median ${ }^{20}$ of the length of employment spells after UBJ. A change for the elderly relative to the younger unemployed over time might be an indication that more generous financial support may result in a better match of employee and job and therefore higher employment stability. This is not found empirically since the elderly do not improve over time compared to the younger unemployed. It is also apparent that the median is highest for 1988 because employment stability was highest during the reunification boom with low unemployment rates during the time period 1990 to 1992.

Another important proxy for the quality of the subsequent match is the wage. Denote $w_{p}$ as the wage of the unemployed in the previous employment and denote $w_{f}$ as the wage in the future employment. In the following, let us consider the transition from the position of $w_{p}$ in the wage distribution $(F)$ in the year when the unemployment spell begins $\left(t_{1}\right)$ to the position of $w_{f}$ in $F$ in the year when the unemployment spell ends $\left(t_{2}\right)$. Denote $\Delta F_{t_{1}}=F_{t_{2}}\left(w_{f}\right)-F_{t_{1}}\left(w_{p}\right)$ as the change in the position in the wage distribution. $\Delta F_{t}$ has an intuitive meaning: it is negative (positive) if the future wage is in a lower (higher) position in the population wage distribution than the previous wage. An extension of the maximum entitlements period should allow the unemployed to spend more time in waiting for the same job offer compared to an individual without extended entitlements. This should increase the expected $\Delta F_{t}$ for the treated individuals and therefore result in a shift of the distribution of $\Delta F_{t}$ to the right.

Table 3 presents the summary statistics for $\Delta F_{t}$ for the full time employees in the different age groups. It is evident that the distributions for the age groups are almost time invariant. ${ }^{21}$ The increase of the maximum entitlement period is not associated with a shift of the distributions for the treated individuals to the right. The changes in the distributions are mainly due to the business cycle. Surprisingly, between $50-60 \%$ of the considered group of unemployed reach after the unemployment period a higher position in the wage distribution compared to before unemployment.

Another way to assess the impact of the reform on future earnings is to use a difference-indifferences method by including age dummies in a regression model. The following Tobit regression

\footnotetext{
${ }^{20}$ The median is chosen because many long employment spells are censored at the data end of 1997 . This affects in particular the average values in the 1990ties.

${ }^{21}$ Nonparametric density estimates of the distributions are also time invariant over 1980, 1985, 1990 , and 1994.
} 
model is estimated:

$$
\log \left(w_{f}^{*}\right)=\alpha+\beta^{\prime} x_{1}+\gamma^{\prime} \mathbb{1}_{\text {age group, year }}+\delta^{\prime} x_{2}+\epsilon,
$$

where $w_{f}^{*}=\min \left\{w_{f}, c\right\}, x_{1}$ is a vector of exogenous observable variables, and $x_{2}$ is a vector of variables which control for the unobserved heterogeneity (such as the wage $w_{p}$ in the previous job, the duration of unemployment, and unemployment experience). $\mathbb{1}_{\text {age group, year }}$ is a $14 \times 1$ dummy vector for the age groups, the calender years and the cross terms, i.e. the treatment effects (see table 4 for details). We choose the untreated individuals (aged $<42$ ) and the year before the reform (1981) as reference category. $\epsilon$ is the error term. The censoring of the wage distribution from above ( $c$ is the topcoding value) is due to the upper threshold for social security taxation above which wages are not reported. Two models are estimated: one basic model, where the error term is in fact the convolution of $\epsilon$ and the unobserved heterogeneity, and one model that controls for $x_{2}$ as proxying unobserved heterogeneity. From the results in table 4 it is not apparent that the reform of the maximum entitlements periods had an effect on the earnings of the elderly, since none of the estimated coefficients for the treatment effects are significantly positive and just one of the significant coefficients indicate a positive treatment effect (age 44-48 in 1985). These results are in contrast to Gangl (2002) who finds based on the German Socioeconomic Panel that more generous payments of unemployment benefits weakens the negative effect of unemployment on the quality of employment after unemployment.

\section{Conclusions}

This paper provides a descriptive analysis of the duration of nonemployment and unemployment between jobs before and after the changes during the mid 1980s in the maximum entitlement period for unemployment benefits for older workers. The analysis develops a theoretical framework in order to interpret differences between nonemployment and unemployment between jobs. The most striking result is that the average duration of nonemployment for elderly unemployed has increased sharply after the reform under consideration whereas the duration of unemployment between jobs does not seem to be affected. This is probably because unemployment benefits were used as an integral part of early retirement packages. Due to the reform, the companies - and even the public sector - obtained a convenient instrument in order to disband elderly employees with the help of social compensation plans. Since the elderly employees did approve of such generous retirement packages, they didn't insist on their dismissal protection. This is a typical win-win situation on the expense of the general public. An increase in the usage of early retirement is also strongly suggested both by the increase in the inflows of elderly workers into nonemployment, 
especially in the economic recession after the reform, compared to the fact that inflows of the elderly into unemployment between jobs did not rise after the reform. The results emphasize that it is indispensable to distinguish between the flows out of labor force and the flows back into employment among the elderly (>53 years) unemployed.

One surprising aspect of our descriptive results is the fact that the duration of unemployment between jobs among the elderly did not seem to change after the reform, i.e. the duration of unemployment between jobs did not increase for this group, which is in contrast to the findings of Hunt (1995) and others in the literature. In fact, the behavior of the unemployed who are willing to accept a new job before and after the reform does not seem to be affected by the reform considered here. Our results also suggest that the varying macroeconomic environment may affect the job search behavior for the considered age groups in a different manner. It is not possible to infer from this paper how many unemployed were induced not to accept a new job at all due to the reform. Finally, our results suggest that extended benefit entitlements for unemployed do not result in a better job match resulting in employment job stability or higher earnings. Further research using more structural methods will be useful to assess whether our descriptive results are robust.

\section{Appendix: tables and figures}

Table 1: Maximum entitlements for unemployment benefits (UB) before and after the reform (in months).

\begin{tabular}{lrrrr}
\hline \hline Age group & until December 1984 & January $1985-$ & January $1986-$ & from July 1987 \\
& & December 1985 & December 1987 & \\
\hline$<42$ & 12 & 12 & 12 & 12 \\
$42-43$ & 12 & 12 & 12 & 18 \\
$44-48$ & 12 & 12 & 16 & 22 \\
$49-53$ & 12 & 18 & 20 & 26 \\
$>53$ & 12 & 18 & 24 & 32 \\
\hline \hline
\end{tabular}

Source: Bundesgesetzblatt 1983-1988, Hunt (1995) 
Table 2: Number of observed unemployment durations starting in the respective year

\begin{tabular}{|c|c|c|c|c|c|c|c|c|}
\hline Age group & 1981 & 1983 & 1985 & 1987 & 1989 & 1991 & 1993 & 1995 \\
\hline \multicolumn{9}{|c|}{ Nonemployment (NE) } \\
\hline$<42$ & 16.281 & 16.401 & 16.262 & 15.738 & 13.115 & 12.848 & 16.144 & 14.810 \\
\hline $42-43$ & 839 & 792 & 640 & 503 & 500 & 547 & 776 & 746 \\
\hline $43-48$ & 1.551 & 1.915 & 1.875 & 1.623 & 1.235 & 1.141 & 1.578 & 1.613 \\
\hline $49-53$ & 1.112 & 1.256 & 1.382 & 1.526 & 1.292 & 1.400 & 1.755 & 1.332 \\
\hline$>53$ & 1.826 & 1.906 & 1.846 & 1.900 & 1.709 & 2.117 & 3.168 & 3.033 \\
\hline \multicolumn{9}{|c|}{ Unemployment between Jobs (UBJ) } \\
\hline$<42$ & 9.493 & 9.677 & 10.544 & 9.989 & 8.134 & 7.185 & 9.241 & 8.093 \\
\hline $42-43$ & 538 & 498 & 435 & 333 & 330 & 326 & 420 & 392 \\
\hline $43-48$ & 993 & 1.195 & 1.299 & 1.098 & 780 & 640 & 867 & 875 \\
\hline $49-53$ & 619 & 723 & 938 & 934 & 841 & 785 & 822 & 595 \\
\hline$>53$ & 672 & 715 & 816 & 710 & 579 & 582 & 684 & 672 \\
\hline
\end{tabular}


Table 3: Descriptive Statistics for the computed $\Delta F_{t}(w)$ : average values, sample variances in brackets and the percentage of observations with positive value.

\begin{tabular}{lrrrrr}
\hline \hline Age group & 1981 & 1985 & 1990 & 1994 \\
\hline$<42$ & & $0.0295(0.0362)$ & $0.0369(0.0348)$ & $0.0415(0.0362)$ & $0.0198(0.0345)$ \\
& $>0$ & $59 \%$ & $61 \%$ & $61 \%$ & $57 \%$ \\
$42-43$ & & $-0.0019(0.0285)$ & $-0.0137(0.0344)$ & $-0.0017(0.0347)$ & $-0.0153(0.0393)$ \\
& $>0$ & $54 \%$ & $51 \%$ & $54 \%$ & $50 \%$ \\
$44-48$ & & $-0.0083(0.0293)$ & $-0.0088(0.0340)$ & $-0.0006(0.0350)$ & $-0.0238(0.0384)$ \\
& $>0$ & $54 \%$ & $53 \%$ & $53 \%$ & $47 \%$ \\
$49-53$ & & $-0.0032(0.0270)$ & $-0.0244(0.0301)$ & $0.0080(0.0275)$ & $-0.0364(0.0397)$ \\
& $>0$ & $55 \%$ & $50 \%$ & $57 \%$ & $48 \%$ \\
$>53$ & & $-0.0025(0.0286)$ & $-0.0184(0.0268)$ & $0.0125(0.0230)$ & $-0.0067(0.0347)$ \\
& $>0$ & $57 \%$ & $48 \%$ & $59 \%$ & $55 \%$ \\
\hline \hline
\end{tabular}


Table 4: Results of Tobit regression of wage in new job after unemployment.

\begin{tabular}{|c|c|c|c|c|}
\hline \multirow[b]{2}{*}{ variable } & \multicolumn{2}{|c|}{ basic model } & \multicolumn{2}{|c|}{ unobserved heterogeneity } \\
\hline & & t-value & & t-value \\
\hline const & $4.1650^{*}$ & 667.8544 & $2.7641^{*}$ & 123.5678 \\
\hline female & $-0.2701^{*}$ & -51.2730 & $-0.1507^{*}$ & -29.3110 \\
\hline married & $0.1477^{*}$ & 29.9222 & $0.0630^{*}$ & 14.0086 \\
\hline female $^{*}$ married & $-0.1768^{*}$ & -20.8681 & $-0.1493^{*}$ & -19.5119 \\
\hline citizenship & $-0.0342^{*}$ & -5.0147 & $-0.0436^{*}$ & -7.0584 \\
\hline skilled & $0.1556^{*}$ & 37.5522 & $0.0400^{*}$ & 10.3488 \\
\hline university degree & $0.4897^{*}$ & 36.0653 & $0.2518^{*}$ & 19.9314 \\
\hline $\log \left(w_{p}\right)$ & - & & $0.3594^{*}$ & 69.1368 \\
\hline$w_{p}$ left-censored & - & & $1.1017^{*}$ & 41.9865 \\
\hline$w_{p}$ right-censored & - & & $1.9586^{*}$ & 64.7698 \\
\hline length of unemployment spell & - & & $-0.0000^{*}$ & -4.3668 \\
\hline recently unemployed before & - & & $-0.0490^{*}$ & -12.5614 \\
\hline previously recalled & - & & $0.0674^{*}$ & 13.9588 \\
\hline age group 42-43 & $0.0966^{*}$ & 5.4078 & $0.0316^{*}$ & 1.9601 \\
\hline age group $44-48$ & $0.0566^{*}$ & 4.1460 & 0.0071 & 0.5746 \\
\hline age group 49-53 & $0.0374^{*}$ & 2.2172 & -0.0076 & -0.5048 \\
\hline age group > 53 & $0.0614^{*}$ & 3.8126 & 0.0013 & 0.0904 \\
\hline age group $42-43 \times 1985$ & -0.0215 & -0.8038 & -0.0281 & -1.1647 \\
\hline age group $44-48 \times 1985$ & $0.0354^{*}$ & 1.9736 & 0.0115 & 0.7095 \\
\hline age group $49-53 \times 1985$ & 0.0357 & 1.6648 & 0.0036 & 0.1882 \\
\hline age group $42-43 \times 1990-1994$ & $-0.0810^{*}$ & -3.2872 & $-0.0639^{*}$ & -2.8703 \\
\hline age group 44-48 × 1990-1994 & 0.0156 & 0.8739 & 0.0061 & 0.3799 \\
\hline age group 49-53 × 1990-1994 & 0.0328 & 1.6122 & 0.0183 & 1.0050 \\
\hline age group $>53 \times 1985-1994$ & 0.0035 & 0.1861 & -0.0043 & -0.2536 \\
\hline 1985 & $0.1083^{*}$ & 18.5624 & $0.0791^{*}$ & 15.2591 \\
\hline 1990 & $0.2880^{*}$ & 45.4523 & $0.1909^{*}$ & 33.7011 \\
\hline 1994 & $0.4030^{*}$ & 65.4637 & $0.2517^{*}$ & 44.5560 \\
\hline$\sigma^{2}$ & 0.1302 & & 0.1066 & \\
\hline Log-likelihood & -15218.172 & & -11582.154 & \\
\hline Nobs, Nvars & 37438,21 & & 37438,27 & \\
\hline \# of censored & 171 & & 171 & \\
\hline
\end{tabular}

*: significant at the $5 \%$ level 
Survival functions before policy change

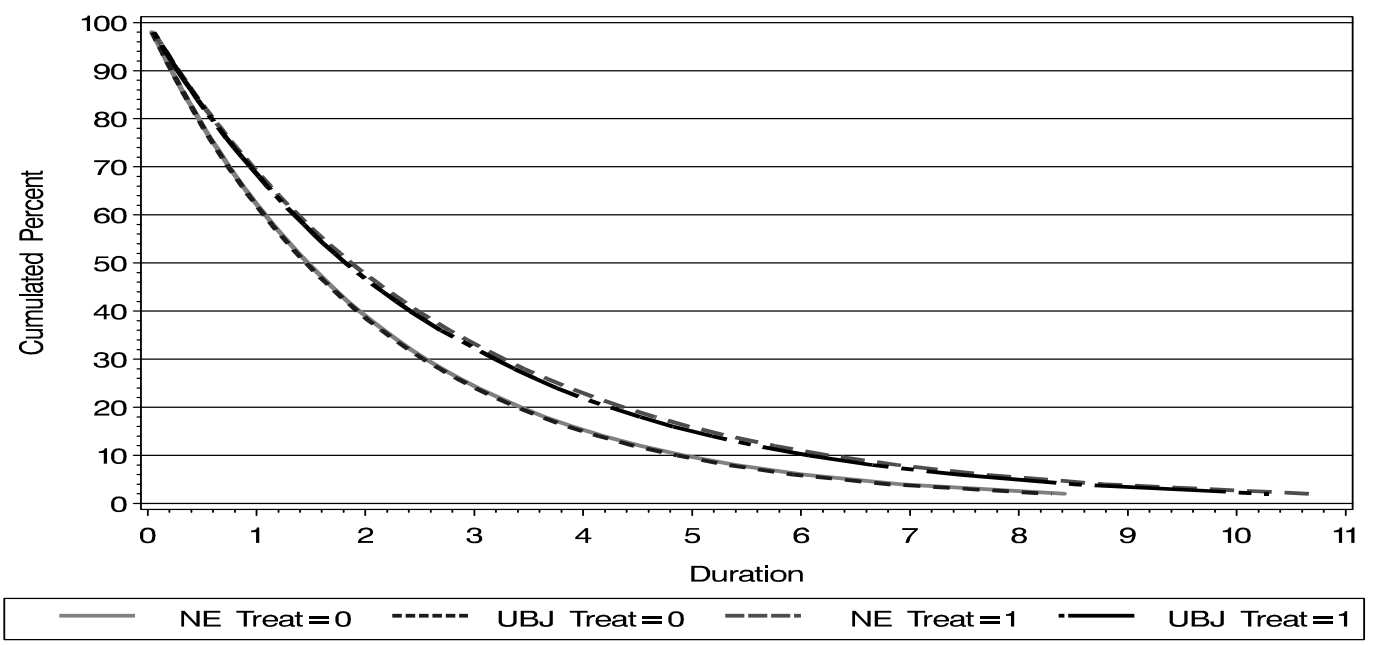

Survival functions after policy change

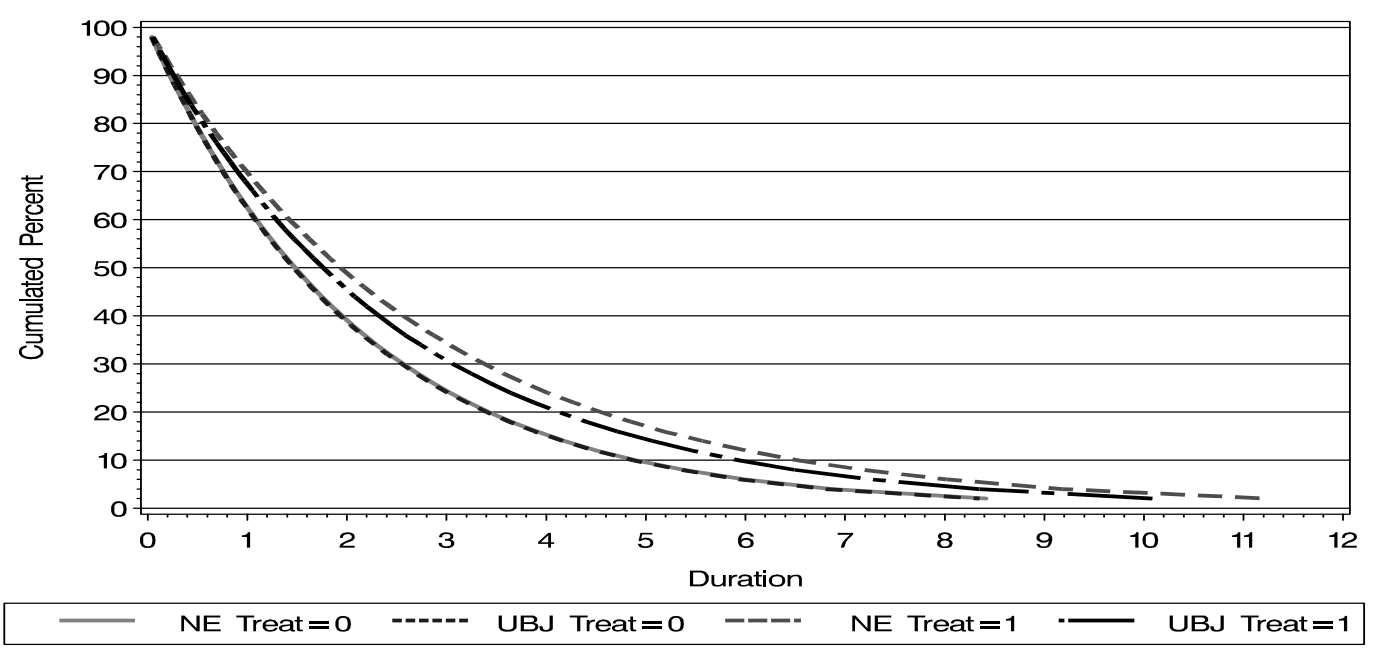

Before-after-change in survival functions for treated population

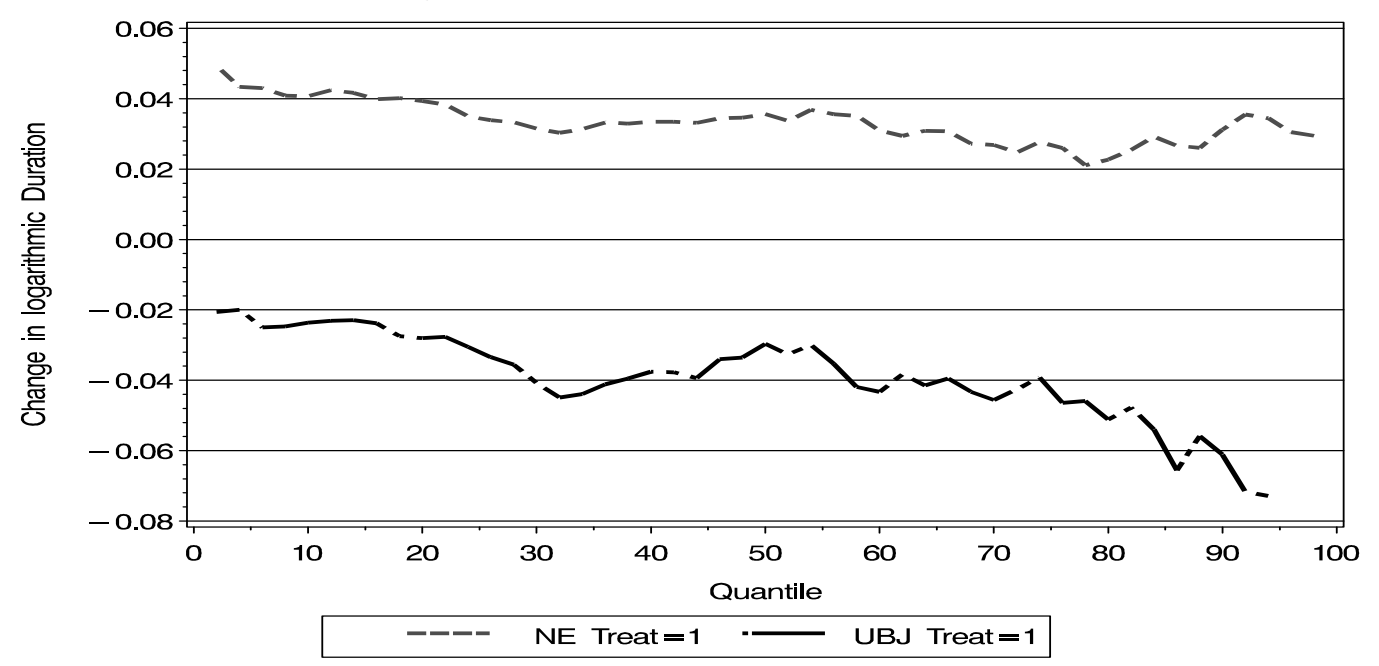

Figure 1: Simulation Results regarding survival functions of NE and UBJ durations 


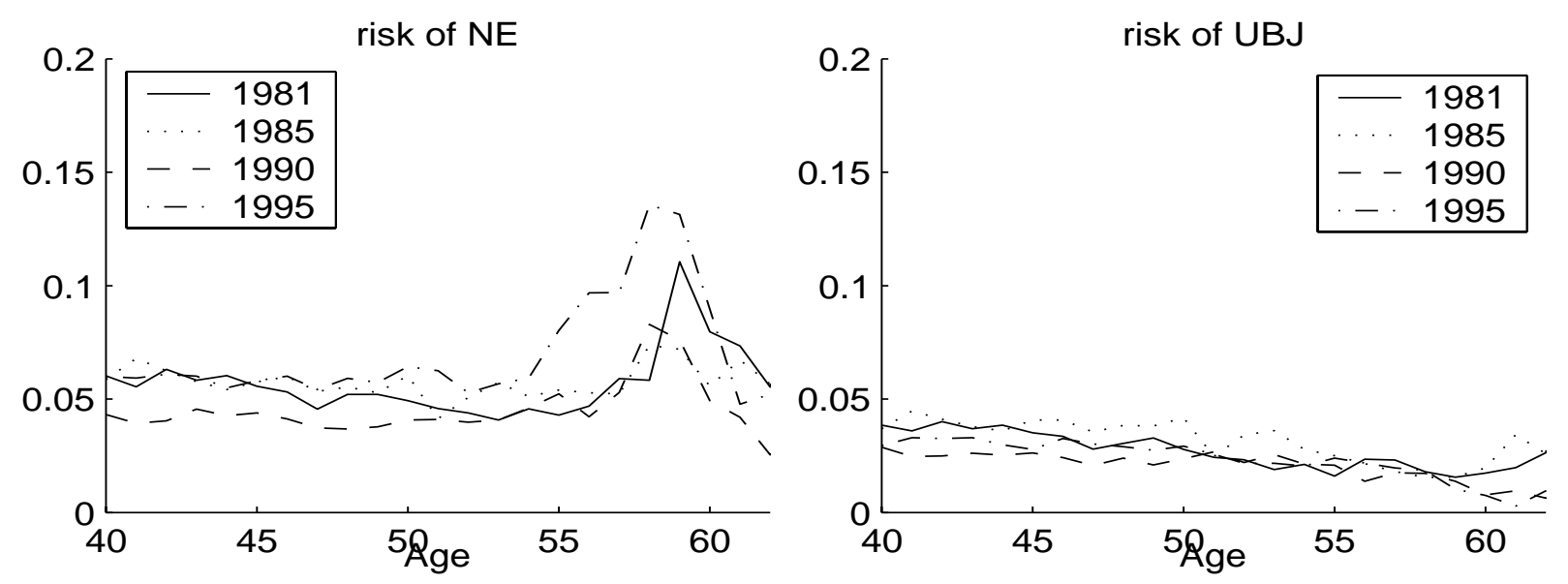

Figure 2: Average risk of unemployment as a function of the age
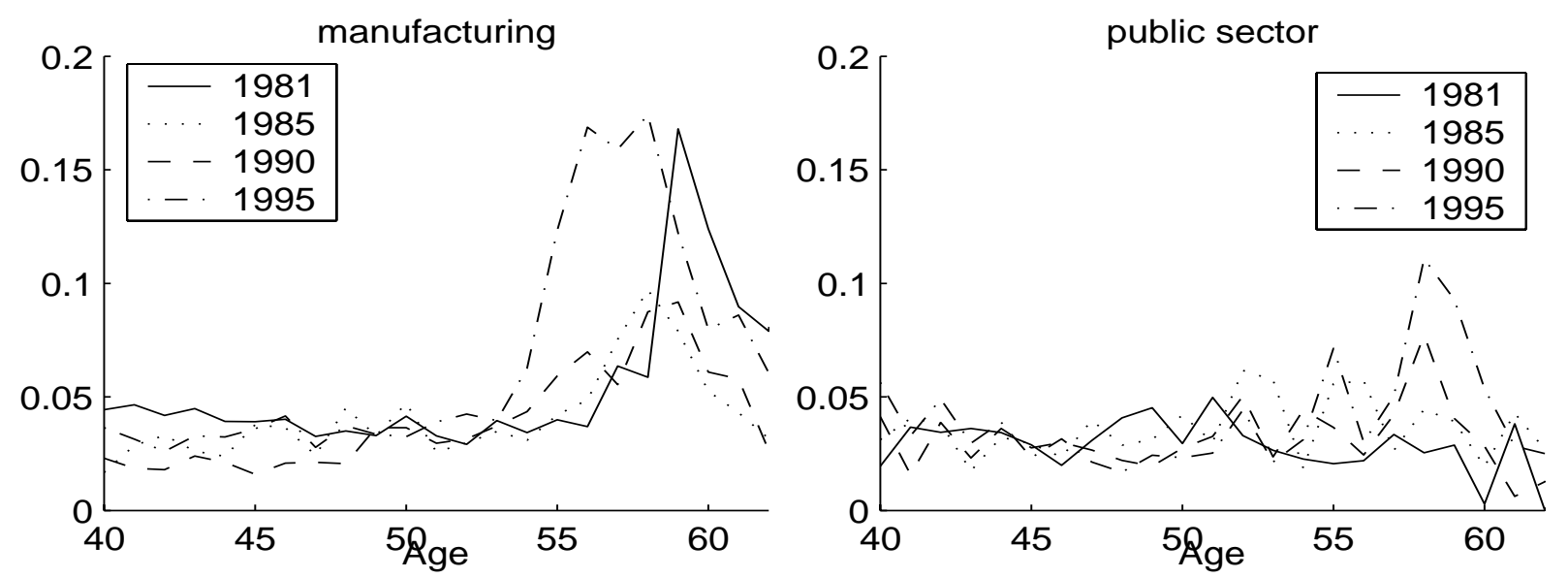

Figure 3: Average risk of nonemployment in selected business sectors

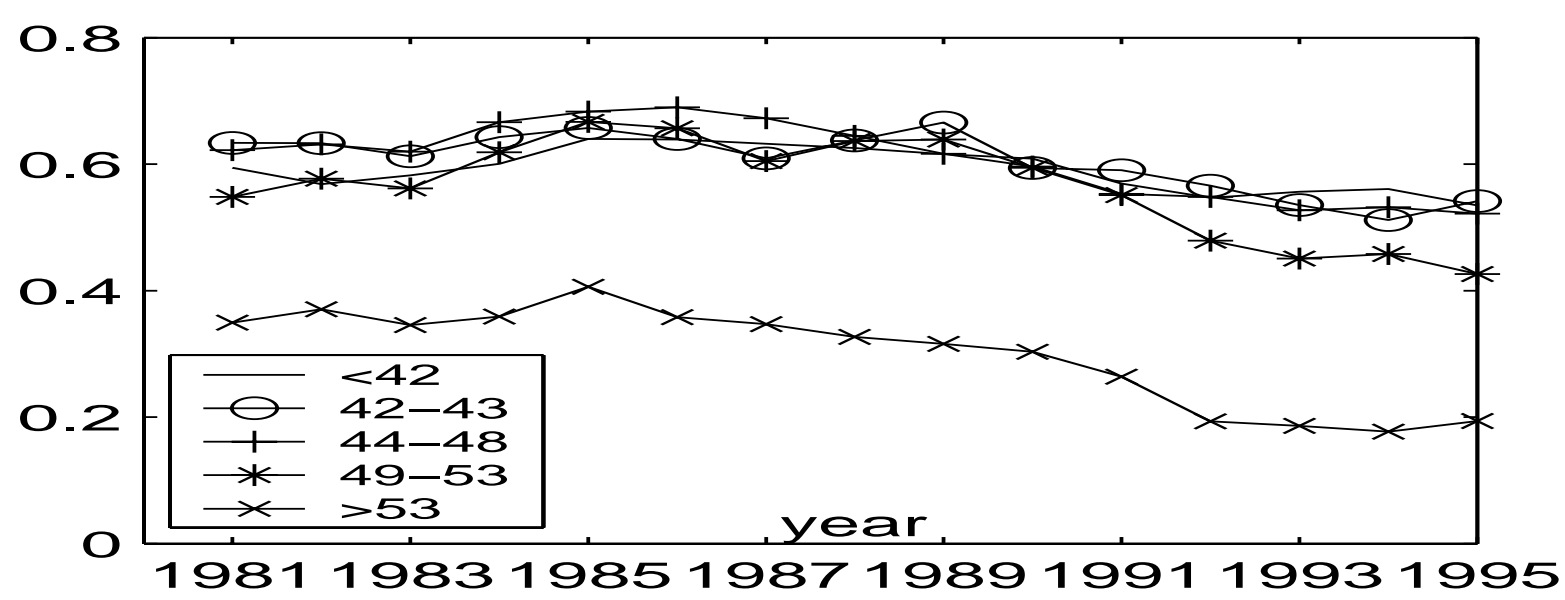

Figure 4: Average risk of unemployment between jobs given nonemployment 

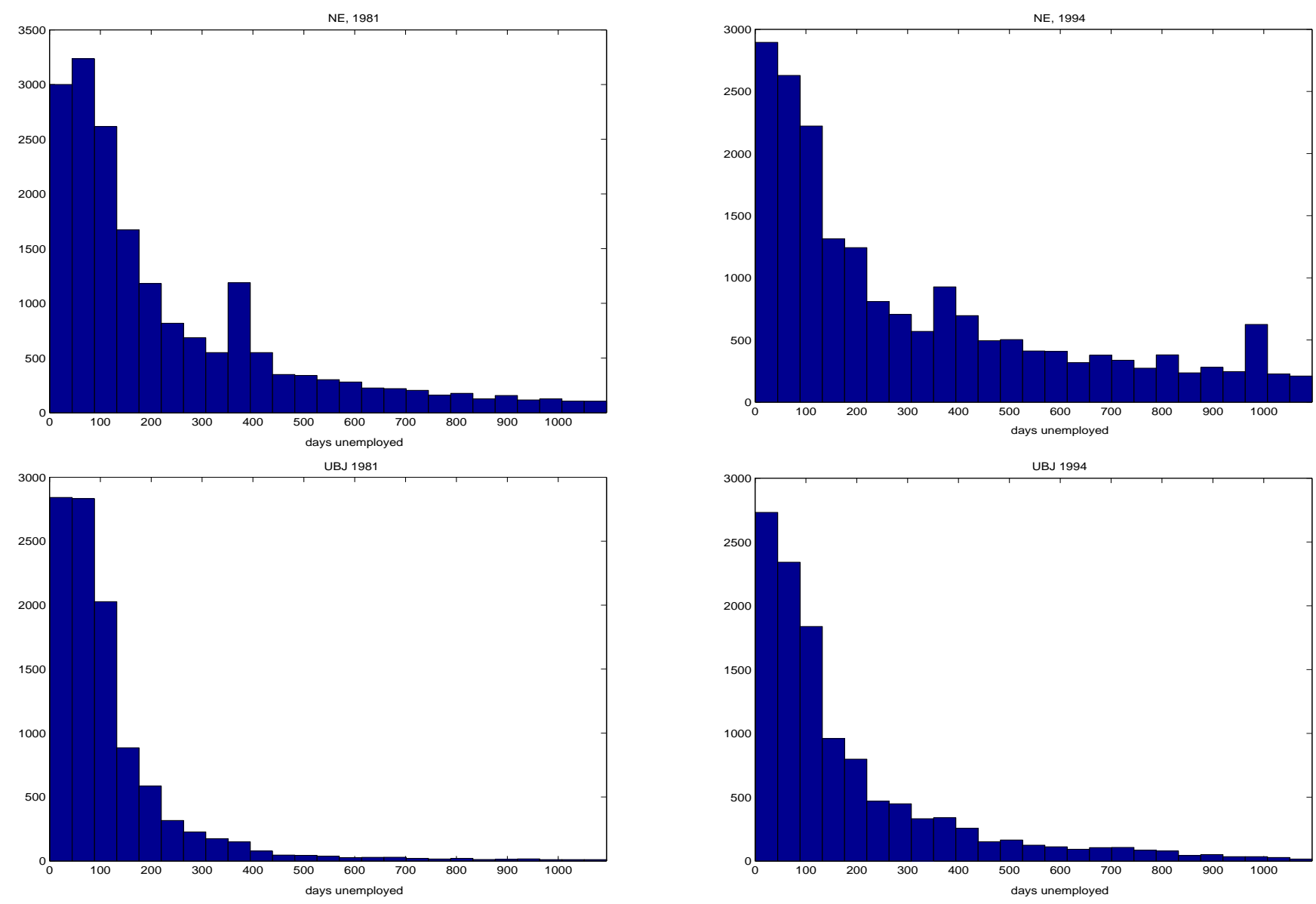

Figure 5: Histogramm of the length of observed unemployment durations in 1981 and 1994.
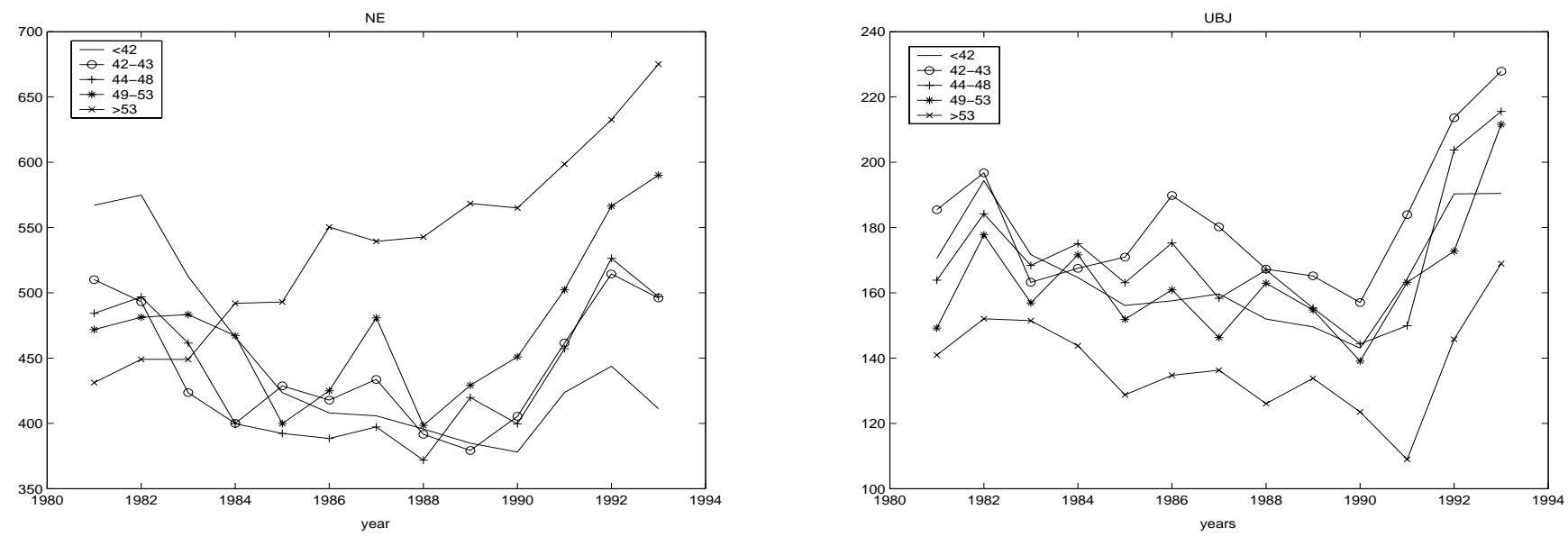

Figure 6: Evolution of average unemployment durations in days over the years under consideration 



Figure 7: Kaplan-Meier-survival function estimates 

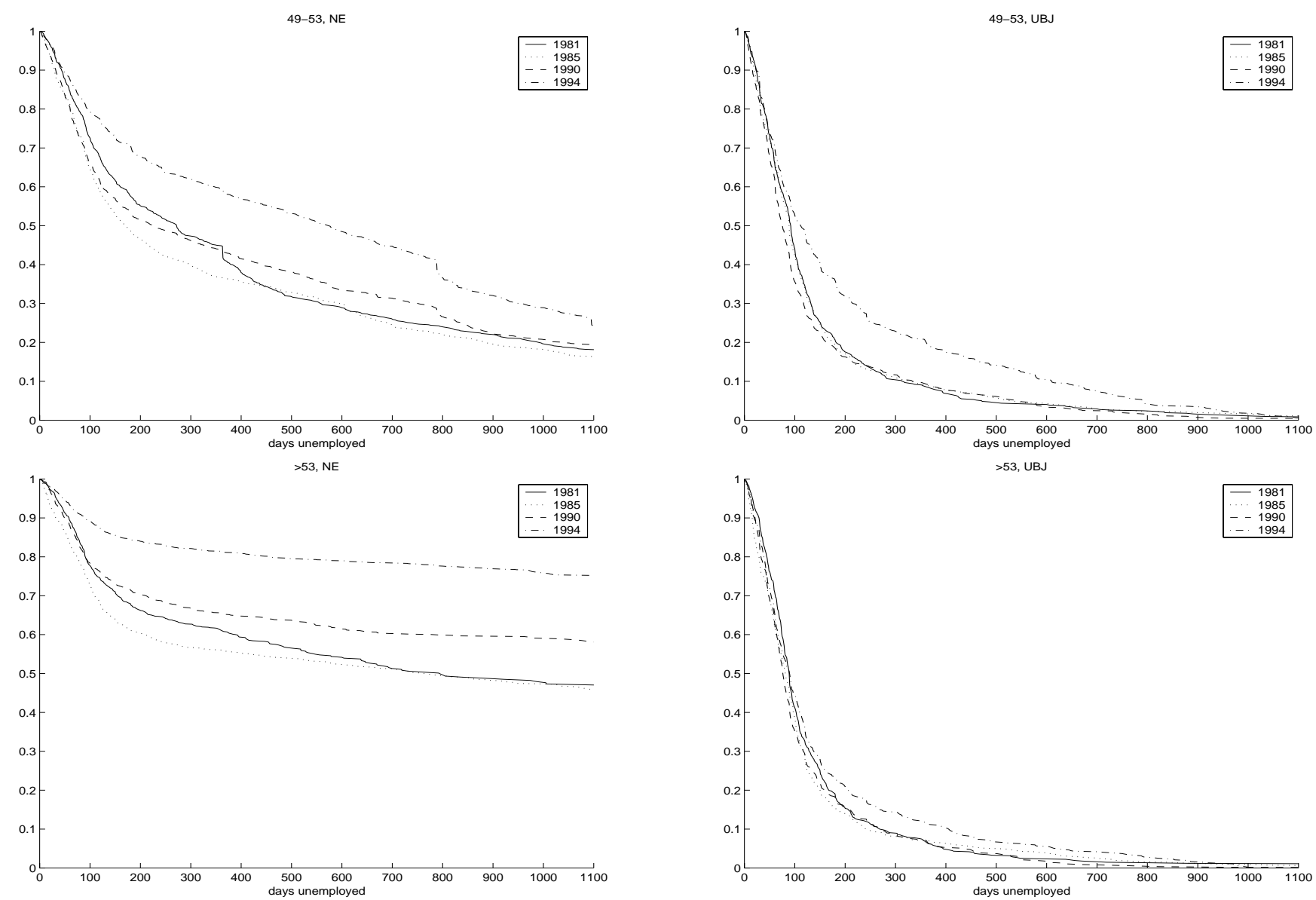

Figure 8: Kaplan-Meier-survival function estimates 

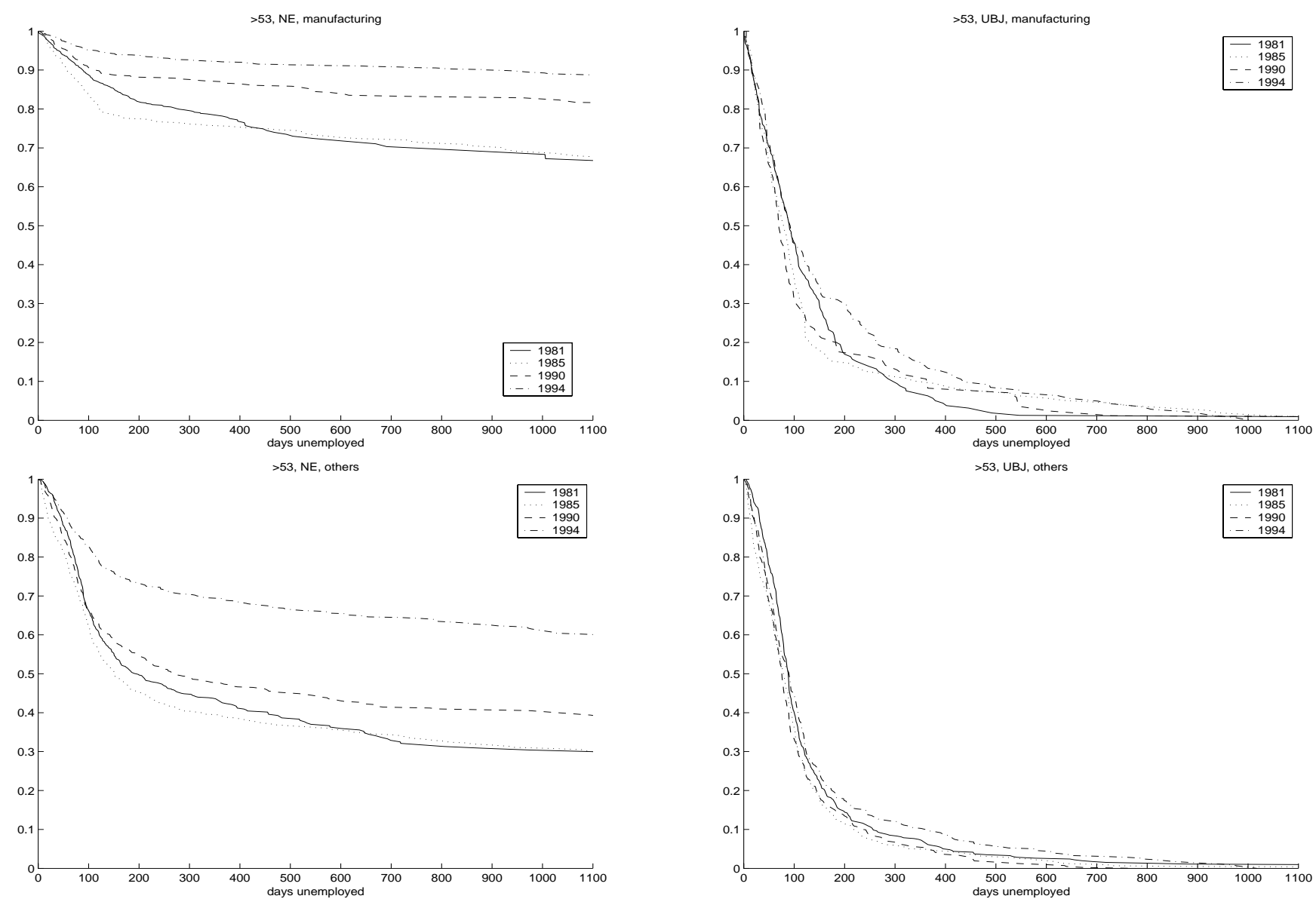

Figure 9: Kaplan-Meier-survival function estimates stratified by business sectors


Figure 10: Empirical survival function estimates for age group $>53$ years stratified by business sector 

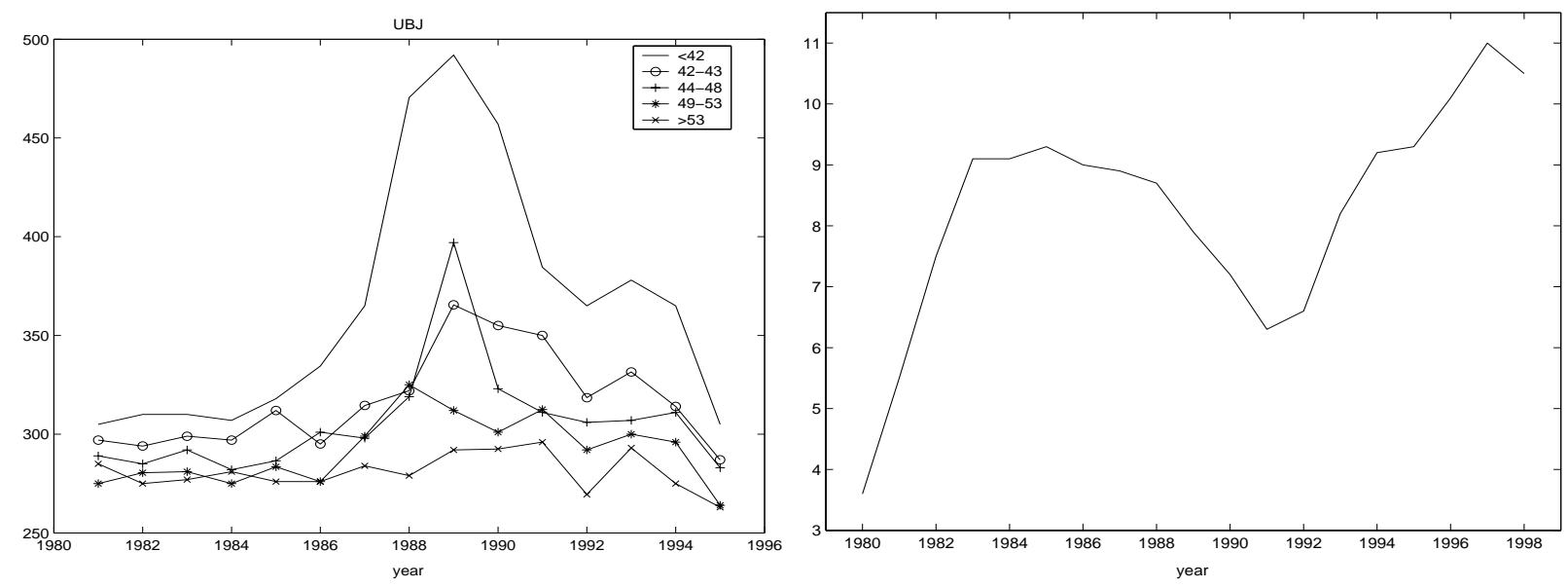

Figure 11: Median of employment spells after UBJ in days for respective years (left), unemployment rates for West-Germany (right) 


\section{References}

Bender, S., Haas, A., and Klose, C. (2000) The IAB Employment Subsample 1975-1995. Schmollers Jahrbuch, 120, 649-662.

Berkel, B. and A. Börsch-Supan (2003) Renteneintrittsentscheidungen in Deutschland: Langfristige Auswirkungen verschiedener Reformoptionen. Unpublisched Manuscript, MEA, Mannheim.

Franz, W. (2003) Arbeitsmarktökonomik. 5th Edition, Springer, Berlin/Heidelberg.

Gangl, M. (2002) Unemployment Benefits as a Search Subsidy: New Evidence on Duration and Wage Effects of Unemployment Insurance. Discussion Paper, FS I 02-208, Wissenschaftszentrum Berlin.

Hujer, R. und Schneider, H. (1995) Institutionelle und strukturelle Determinanten der Arbeitslosigkeit in Westdeutschland: Eine mikroökonomische Analyse mit Paneldaten. In: B. Gahlen, H. Hesse, H.J. Ramser, editors, Arbeitslosigkeit und Möglichkeiten ihrer Überwindung, Wirtschaftswissenschaftliches Seminar Ottenbeuren, 25, J.C.B. Mohr, Tübingen, 53-76.

Hunt, J. (1995) The effect of the Unemployment Compensation on Unemployment Duration in Germany. Journal of Labor Economics. Vol. 13.1, 88-120.

Katz, F., and Meyer, B. (1990) The impact of the potential duration of unemployment benefits on the duration of unemployment. Journal of Public Economics. Vol. 41, 45-72.

Koller, B. Bach, H.-U. and U. Brixy (2003) Ältere ab 55 Jahren - Erwerbstätigkeit, Arbeitslosigkeit und Leistungen der Bundesanstalt für Arbeit. IAB-Werkstattbericht Nr. 5/2003, Nürnberg.

Narendranathan W., Nickell, S. and Stern J. (1995) Unemployment Benefits Revisited. The Economic Journal Vol. 95, 307-329.

Plaßmann, G. (2002) Der Einfluss der Arbeitslosenversicherung auf die Arbeitslosigkeit in Deutschland. Beiträge zur Arbeitsmarkt-- und Berufsforschung, 255, Institut für Arbeitsmarkt- und Berufsforschung der Bundesanstalt für Arbeit (IAB) Nürnberg.

Solon, G. (1985) Work Incentive Effects of Taxing Unemployment Benefits. Econometrica, Vol. $53.2,295-306$. 
Steiner, V. (2001) Unemployment Persistence in the West German Labour Market: Negative duratin Dependance or Sorting?, Oxford Bulletin of Economics and Statistics Vol. 63, 91113.

Van den Berg, G.H. (1990) Nonstationarity in Job Search Theory. Review of Economic Studies Vol.57, 255-277.

Van den Berg, G.H. (2001) Durations Models: Specification, Identification and Multiple Durations. In: J.J. Heckman, E. Leamer, editors, Handbook of Econometrics, Volume 5, Elsevier, Amsterdam, pp. 3381-3460.

Wilke, R. (2003) Eine empirische Analyse von Sanktionen für Arbeitslose in Westdeutschland während der 1980er und 1990er Jahre. ZEW-Discussion Paper No. 03-71.

Wilke, R. (2004) Exploring the risk of unemployment and the duration of unemployment of the 26-41 aged workforce in West-Germany during the 1980ties and 19990ties. Mimeo. ZEW Mannheim.

Wolff, J. (2003) Unemployment compensation and the duration of unemployment in East Germany Sfb 386 Discussion Papers 344 . University of Munich 